\title{
Study of Interstitial Lung Disease With Reference to Radiological Profile
}

\author{
S. Annapurna ${ }^{1}$, Pankaj Badarke ${ }^{2}$, Eshwar Chandra ${ }^{3}$ \\ ${ }^{1}$ Assistant Professor, Department Of Radiology, Kamineni Academy Of Medical Sciences And Research Centre, Hyderabad, ${ }^{2}$ Assistant Professor, Department Of \\ Radiology, Government Medical College, Akola, ${ }^{3}$ Head of Department, Department of Radiology, Virichi Hospital,Hyderabad.
}

\begin{abstract}
Background: Interstitial lung disease Diagnosis requires extensive investigation into the patient's symptoms, life style, work history, exposures, and medications forming the clinical context. Subjects and Methods: The cross sectional perspective and high spatial resolution makes HRCT superior to other imaging modalities like chest X-Ray, lung tomography and conventional CT Scanning multiplanar imaging with aim to determine the radiological profile in a clinically suspected cases of Interstitial Lung Disease the present study conducted over 50 patients during the period of 12 months from October 2012 to October 2013 in kamineni hospital, Hyderabad. Results: Out of 50 clinically suspected patients of interstitial lung disease, a specific pattern was observed in 44patients on HRCT and 33 patients on chest radiograph. Patterns found on chest radiograph were correlated with patterns found on HRCT. Out of 44 interstitial lung diseases on HRCT, 28 patients revealed correlation between chest radiograph and HRCT pattern. Out of 50, thirty one patients had correlation between Chest radiograph and HRCT findings. Conclusion: HRCT is superior to chest radiograph in detection of all basic patterns associated with ILD and scores more in their distribution and lung parenchymal involvement.
\end{abstract}

Keywords: Interstitial Lung Disease, HRCT Patterns, Interstitial Pneumonia.

Corresponding Author: Dr. Pankaj Badarke, Assistant Professor, Department Of Radiology, Government Medical College, Akola.

Received: August 2018

Accepted: September 2018

\section{Introduction}

Interstitial lung disease (ILD), an umbrella diagnosis given to a variety of diffuse parenchymal lung diseases, refers to a heterogeneous group of over 150 unrelated disorders. It encompasses a plethora of parenchymal lung disorders with common functional characteristics such as restrictive physiology, impaired gas exchange and with variable degrees of pulmonary inflammation and fibrosis. ${ }^{[1,2]}$

A distinct clinical presentation as well as radiographic and pathologic findings characterizes each ILD form. Several key differences between the clinical presentation of the more frequent obstructive lung disease diagnosis and an ILD diagnosis are due to differences in the anatomic disease distribution. In most cases the pathology of ILD lies in the pulmonary interstitium, which consists primarily of connective tissue and refers to the space between the alveolar epithelial cells and the adjacent capillary endothelial cells. Diagnosis of ILD requires extensive investigation into the patient's symptoms, life style, work history, exposures, and medications forming the clinical context. $^{[3]}$

Two-thirds of ILD cases have no reported etiology. ${ }^{[4]}$ The remaining one-third may be associated with various environmental or occupational factors including cigarette smoking, aspiration, certain drugs, radiation therapy, cancer, and systemic diseases with lung involvement. ${ }^{[5]}$ Extensive environmental and occupational exposure history is thus essential as it may lead to identification of a specific cause for ILD. ${ }^{[6]}$

Chest radiograph (CXR) is an easily available, non-invasive investigation but it shows few abnormalities and is abnormal in only $80 \%$ of cases. ${ }^{[7]}$ So It cannot be used as specific diagnostic investigation. Pulmonary function testing (PFTs) includes spirometry (with and without bronchodilator) and plethysmographic lung volumes. But, PFTs cannot diagnose a specific ILD or distinguish between active lung inflammations versus fibrosis and are critically important in the objective assessment of respiratory symptoms as well as in comparing the differential diagnosis, grading the severity of disease, and monitoring. ${ }^{[8]}$ HRCT is the most accurate noninvasive imaging modality for evaluation of lung parenchyma. The cross sectional perspective and high spatial resolution makes HRCT superior to other imaging modalities like chest X-Ray, lung tomography and conventional CT Scanning.

With respect to interstitial diseases, the role of HRCT is to:

- Diagnose and characterize the type of disease

- Detect the presence of active lung disease

- To determine the most appropriate site for biopsy

- Change in disease activity following treatment.

HRCT can detect normal and abnormal lung interstitium and morphological characteristics of both localized and diffuse lung disease. So it has become invaluable tool in characterization of interstitial lung disease (ILD) in appropriate clinical setting. HRCT along with laboratory tests, physiological studies and invasive procedures is a useful tool in arriving at differential diagnosis or final 


\section{Annapurna et al; Interstitial Lung Disease With Relerence ta Radialagical Profile}

diagnosis.

HRCT scan is a relatively new radiologic diagnostic modality as compared to conventional chest X-ray. The purpose of this study is to find its role in evaluation \& diagnosis of ILD in our setting.

\section{$\underline{\text { Aim }}$}

To determine the radiological profile in clinically suspected cases of Interstitial Lung Disease

\section{Objective}

1. To study basic HRCT patterns associated with Interstitial Lung Disease.

2. Correlation of HRCT patterns with clinical data in differential diagnosis of Interstitial Lung Disease.

3. To determine correlation between the chest x-ray \& HRCT patterns.

\section{Subjects and Methods}

- A total number of 50 patients with suspected or known interstitial lung disease were studied by high resolution computed tomography (HRCT) over a period of 12 months from October 2012 to October 2013.

- Type of study: prospective and descriptive observational study.

- The study group consists of 50 patients; of whom 18 were males $(36 \%)$ and 32 were females (64\%). The age group of patients varied from 17 years to 82 years.

- Selection Criteria /inclusion criteria:

1. All clinically suspected patients of interstitial lung disease.

2. All patients suspicious of interstitial lung disease on chest radiograph.

3. All patients having restricted lung capacity on pulmonary function test.

4. Known cases of collagen vascular disorders having respiratory symptoms.

5. Patients having history of exposure to allergen $\&$ having respiratory symptoms.

\section{Exclusion criteria}

1. Known cases of infective etiology like Tuberculosis, HIV

2. Known cases of COPD, CCF

3. Known cases of lung malignancy

4. Hemodynamically unstable patients

- Data collected from these patients included their age, sex, occupation, clinical history, risk factor and relevant investigation reports.

- Chest Radiograph: In all patients during initial data collection, chest radiograph was studied and findings of reticular opacities, nodular opacities, reticulonodular opacities, consolidation/ increased opacity, bronchiectasis, cyst, emphysema as decreased opacity were noted.

- After taking informed consent, patients are subjected to examination.

\section{Results}

A total number of 50 patients with suspected or known interstitial lung disease were studied by high resolution computed tomography (HRCT) scanning of lungs over a period of 12 months, in the department of Radiology, Kamineni hospital, LB Nagar, Hyderabad.

\begin{tabular}{|c|c|c|c|c|c|c|}
\hline \multicolumn{7}{|c|}{ Age and Sex Distribution of Studied Patients } \\
\hline \multirow{2}{*}{$\begin{array}{l}\text { Sr. } \\
\text { No }\end{array}$} & \multirow{2}{*}{$\begin{array}{l}\text { Age } \\
\text { group }\end{array}$} & \multirow{2}{*}{$\begin{array}{l}\text { No.of } \\
\text { patients }\end{array}$} & \multicolumn{2}{|c|}{ Male } & \multicolumn{2}{|l|}{ Female } \\
\hline & & & No & $\%$ & No & $\%$ \\
\hline Male & Female & Male & Female & Male & Female & Male \\
\hline No & $\%$ & No & $\%$ & No & $\%$ & No \\
\hline Male & Female & Male & Female & Male & Female & Male \\
\hline No & $\%$ & No & $\%$ & No & $\%$ & No \\
\hline Male & Female & Male & Female & Male & Female & Male \\
\hline No & $\%$ & No & $\%$ & No & $\%$ & No \\
\hline
\end{tabular}

The most common age group was sixth to eight decades followed by fourth to sixth decade in both males and females. Female preponderance was noted with female: male ratio of $1.7: 1$

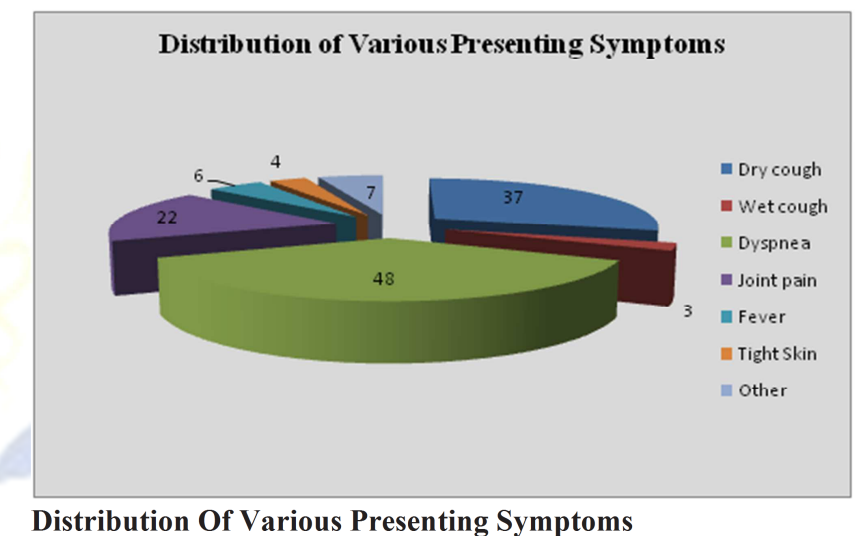

The most common presenting symptom was progressive dyspnea and dry cough followed by joint pain associated with connective tissue disorder.

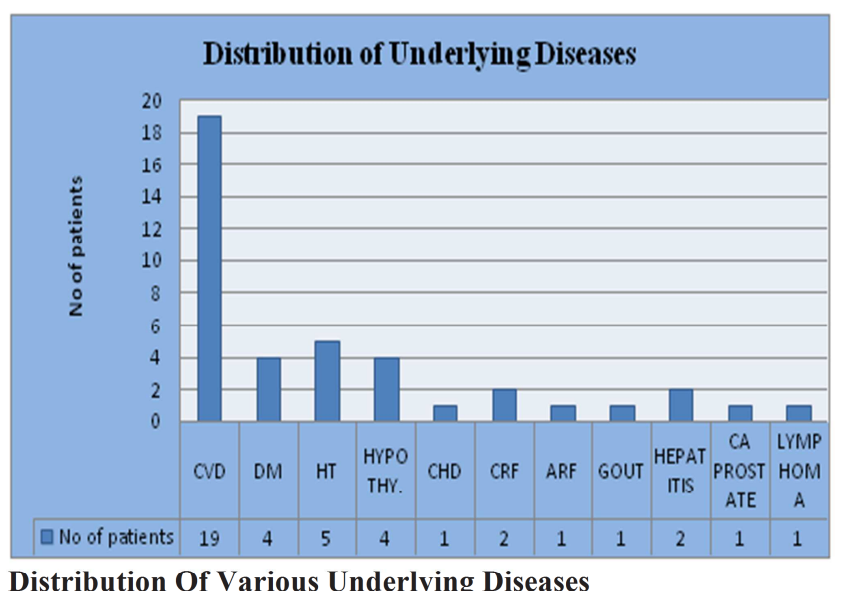

Distribution of Cases By HRCT Diagnosis

Usual interstitial pneumonia / Idiopathic pulmonary fibrosis was the most common HRCT diagnosis in the present study followed by nonspecific interstitial pneumonia and acute interstitial pneumonia. 
Annapurna et al; Interstitial Lung Disease With Reference ta Radialagical Prafile

Distribution Of Associated Risk Factors With HRCT Diagnosis In Fifty Patients

\begin{tabular}{|c|c|c|c|c|c|c|c|c|c|c|}
\hline & Smoker & Allergy & Exposure & RA & SCL & SLE & MCD & WG & Male & Female \\
\hline UIP/IPF & 5 & 2 & 1CT,RT & 3 & 0 & 0 & 0 & 0 & 8 & 10 \\
\hline NSIP & 0 & 0 & 0 & 1 & 3 & 0 & 0 & 0 & 1 & 6 \\
\hline AIP & 3 & 0 & 1CT:ABD & 0 & 0 & 1 & 0 & 0 & 4 & 3 \\
\hline Boop/Cop & 0 & 2 & 0 & 0 & 0 & 0 & 0 & 0 & 1 & 4 \\
\hline Plex.Art. & 0 & 0 & 0 & 0 & 0 & 0 & 1 & 0 & 0 & 2 \\
\hline HP & 0 & 1 & 0 & 0 & 0 & 0 & 0 & 0 & 1 & 0 \\
\hline Coal Worker Pneumoconiosis & 0 & 0 & 1coal mine & 0 & 0 & 0 & 0 & 0 & 1 & 0 \\
\hline Sarcoidosis & 0 & 1 & 0 & 1 & 0 & 0 & 0 & 0 & 0 & 1 \\
\hline Vasculitis & 1 & 0 & 0 & 0 & 0 & 0 & 0 & 1 & 1 & 0 \\
\hline Bronchiolitis & 0 & 0 & 0 & 1 & 0 & 0 & 0 & 0 & 0 & 1 \\
\hline Non Specific & 0 & 2 & 0 & 5 & 0 & 1 & 0 & 0 & 1 & 5 \\
\hline Total & 9 & 8 & 3 & 11 & 3 & 2 & 1 & 1 & 18 & 32 \\
\hline
\end{tabular}

Most common risk factor associated with interstitial lung disease in our study population was connective tissue disorder followed by smoking and allergy history.

\section{Patterns found in fifty suspected cases of interstitial lung diseases on HRCT with chest radiograph corelation}

Distribution of radiological patterns on hrct and xray
\begin{tabular}{|l|l|l|l|l|l|}
\hline & $\begin{array}{l}\text { Reticul } \\
\text { ar } \\
\text { opacitie } \\
\text { s }\end{array}$ & $\begin{array}{l}\text { Nodula } \\
\text { r } \\
\text { opaciti } \\
\text { es }\end{array}$ & $\begin{array}{l}\text { Increase } \\
\text { d } \\
\text { opacity }\end{array}$ & $\begin{array}{l}\text { Decreas } \\
\text { ed } \\
\text { opacity }\end{array}$ & $\begin{array}{l}\text { Other } \\
\text { findin } \\
\text { gs }\end{array}$ \\
\hline HRCT & 37 & 8 & 29 & 29 & 30 \\
\hline $\begin{array}{l}\text { Radiogra } \\
\text { ph }\end{array}$ & 21 & 6 & 10 & 0 & 9 \\
\hline
\end{tabular}

Most commonly found pattern associated with ILD is reticular opacity. Chest radiograph is nonspecific initial investigation to diagnose ILD.

HRCT could demonstrate the different patterns of disease and their distribution in lungs.

\section{Discussion}

A total number of 50 patients with suspected or known interstitial lung disease who were referred to the department of Radiology, Kamineni Hospitals, for HRCT of lungs over a period of twelve months were included in the present study.

Out of 50 cases, Fourty four cases (88\%) showed specific patterns associated with interstitial lung disease and six cases $(12 \%)$ showed nonspecific findings. Out of the six cases, three cases showed no involvement of lung parenchyma.

\section{Comparison Of Age And Sex Distribution With Indian} And Western Studies

\begin{tabular}{|l|l|l|}
\hline Study & Age Group & F:M Ratio \\
\hline Present study & $60-80 \mathrm{yr}$ & $1.7: 1$ \\
\hline Muhammed SK et.al $^{[9]}$ & $40-60 \mathrm{yr}$ & $1.05: 1$ \\
\hline Sen T, Udwadia ZF et.al. ${ }^{[10]}$ & $40-60 \mathrm{yr}$ & $2: 1$ \\
\hline${\text { Maheshwari U, et al. }{ }^{[1]}}$ & $40-60 \mathrm{yr}$ & $1.2: 1$ \\
\hline Aziz ZA, et.al. $^{[12]}$ & $60-80 \mathrm{yr}$ & $1.04: 1$ \\
\hline
\end{tabular}

The study included 18 males and 32 female patients. The most common age group at presentation was 60 to 80 years with 25 patients including 17 females and 8 males. Fifty percent of population included in this study is in between 60 to 80 years of age and majorities were female. Earlier
Indian studies (40-60yr) showed the age of presentation almost two decades earlier than western study (60-80) with predominance of females. ${ }^{[9-12]}$ The age group of our patients is in variance with previously published Indian studies and matches that of western study. This might suggest a change in the Indian life styles towards more westernisation, small sample size and a more urban bias of the study population.

Distribution of symptoms with comparison to indian studies:

\begin{tabular}{|l|l|l|l|}
\hline $\begin{array}{l}\text { Presenting } \\
\text { Complaints }\end{array}$ & $\begin{array}{l}\text { Muhammed } \\
\text { SKet al }^{[9]}\end{array}$ & $\begin{array}{l}\text { Maheshwari U, } \\
\text { et al }^{[11]}\end{array}$ & $\begin{array}{l}\text { Present } \\
\text { Study }\end{array}$ \\
\hline $\begin{array}{l}\text { Progressive } \\
\text { dyspnea }\end{array}$ & $97.2 \%$ & $98.6 \%$ & $96 \%$ \\
$\begin{array}{l}\text { Cough ddry \& } \\
\text { wet }\}\end{array}$ & $90 \%$ & $92.1 \%$ & $80 \%$ \\
\hline Joint symptoms & $15.7 \%$ & $13.2 \%$ & $44 \%$ \\
\hline
\end{tabular}

These findings were in accordance with those reported by Muhammed Sket al, ${ }^{[9]}$ in 2011 . Joint symptoms were more commonly found as compared to literature. This might happened due to more referral bias towards connective tissue disorder from rheumatologist since the inclusion criteria included patients of connective tissue disorder with pulmonary symptoms.

\section{Distribution of associated risk factors with comparison} to indian study:

The most common associated risk factor seen in the present study was connective tissue disorder. A total of 19 patients (38\%) were serologically positive for connective tissue disorder. In the study conducted by Muhammed SK et al, ${ }^{[9]}$ $29 \%$ of study population tested serologically positive for connective tissue disorder. Other associated risk factors recorded in the present study were smoking (18\%), allergy $(16 \%)$. Three patients had history of exposure which included exposure to chemotherapy, radiotherapy in two patients and coal dust particle in coal mine in one patient. Smoking and exposure history as compared to literature was less common. This might have happened due to more females were included in study population, limited sample size and referral bias.

\section{Distribution of interstitial lung diseases and literature comparison:}

In the present study the most common interstitial lung disease reported on HRCT was usual interstitial pneumonia / idiopathic pulmonary fibrosis (36\%). Nonspecific 
interstitial pneumonia and acute interstitial pneumonia were reported in 7 cases (14\%) each. These findings were in accordance with those reported by Muhammed SK et al, ${ }^{[9]}$ Maheshwari U et al, ${ }^{[11]}$ and Sen T Udwadia ZF et al, ${ }^{[10]}$ As compared to literature, more patients of BOOP/COP and AIP were noted in our study and which might be due to sampling error. As opposed to this less patients of hypersensitivity pneumonitis, coal worker pneumoconiosis and sarcoidosis were noted and this might be due to a small sample size.

\section{Distribution of chest radiograph patterns with comparison to indian study:}

The various patterns found to be associated with interstitial lung disease in our study population on chest radiograph were reticular opacities $(\mathrm{n}=21 ; 42 \%)$ followed by increased opacity $(n=10 ; 20 \%)$ and nodular opacities $(n=6 ; 12 \%)$. These findings were well correlated with the findings of Indian study done by Muhammed SK et al. ${ }^{[9]}$

\section{High resolution computed tomography $\{$ HRCT $\}$ :}

The most common HRCT finding observed in present study was septal thickening $(n=37 ; 64 \%)$ followed by bronchiectasis $(n=26 ; 52 \%)$ and ground glass opacity $(n=24 ; 48 \%)$. Diffuse distribution of HRCT findings was seen in 24 cases $(48 \%)$. Lower lobes were predominantly involved in 37 cases $(64 \%)$.

\section{Distribution of HRCT findings with comparison to indian study:}

The various patterns found to be associated with interstitial lung disease in our study population, on HRCT were reticular opacities $(n=37 ; 64 \%)$ followed by increased $\operatorname{opacity}(n=29 ; 58 \%)$ and decreased opacity $(n=29 ; 58 \%)$. These findings were well correlated with the findings of Indian study done by Muhammed SK et.al.[9]which was very similar to our study, except decreased opacity which were not separately described in that study. Decreased opacity was mainly contributed by traction bronchiectasis and in most conditions it was part of reticular opacity.

\section{Distribution of HRCT and chest radiograph patterns as compaired to indian study:}

Most common pattern seen on HRCT and chest radiograph is reticular and linear opacities. These findings correlated with findings of Paslawski $\mathrm{M}$ et al. ${ }^{[13]}$ and Muhammed SK et al. ${ }^{[9]}$ HRCT was superior to chest radiograph in detection of all basic patterns and their distribution associated with ILD. Chest radiograph is a nonspecific investigation and can be utilized as initial investigation in work up of ILD. However, HRCT of lungs along with clinical data is essential for the diagnosis of ILD as reported by Potente G et al, ${ }^{[14]}$ Grenier $\mathrm{P}$ et al, ${ }^{[15]}$ Aziz ZA et al, ${ }^{[16]}$ Raniga $\mathrm{S}$ et $\mathrm{al}^{[17]}$ and Ghulam Shabbier et al. ${ }^{[18]}$

\section{Idiopathic pulmonary fibrosis /usual interstitial pneumonia:}

In the present study we came across eighteen cases $(36 \%)$ of IPF. Out of them eight (44\%) were males and ten $(56 \%)$ were females. Majority of these patients presented with progressive breathlessness and dry cough. Out of 18, five patients were smokers and four patients were serologically positive for connective tissue disorders which included three patients with rheumatoid arthritis and one patient with scleroderma.

Chest radiographs of all patients were studied prior to HRCT examination. The predominant pattern found were reticular opacities in 11 cases, mostly involving lower zone and probably representing changes of fibrosis, septal thickening with associated cystic changes. These findings correlated with findings of Maheshwari U, et al. ${ }^{[1]}$

On HRCT, lower lobe posterior basal segment $(n=18)$ and subpleural areas $(n=16)$ were most commonly affected followed by the involvement of middle lobes and upper lobes suggesting disease process begins in posterior basal region and progressively involves upper regions of lungs. These findings correlated with findings of Maheshwari U, et al, ${ }^{[11]}$ Lim MK et al. ${ }^{[19]}$ and Battista G et al. ${ }^{[20]}$

Honeycombing indicates irreversible and end stage disease and appear as a thick walled small air containing cystic spaces sharing walls and lying in layers in posterior basal regions. Septal thickening, honeycombing and traction bronchiectasis were commonest findings observed in almost all cases seen predominantly in basal and subpleural region corresponded with findings of the studies done by Maheshwari U et al. ${ }^{[11]}$ Akira $M$ et al, ${ }^{[21]}$ Nishiyama $O$ et al. ${ }^{[22]}$ and Misumi $\mathrm{S}$ et al. ${ }^{[23]}$ Ground glass opacities as compared to literature were found more commonly that might be due to active disease and /or superimposed infection. Pulmonary function test was performed in 5 cases before HRCT and all of them showed mild to moderate restriction. Lung volume decreased significantly in 10 cases (56\%) as observed on HRCT. A confident HRCT diagnosis of UIP /IPF in association with typical clinical features will allow the clinician to avoid an unnecessary surgical biopsy.

\section{Nonspecific interstitial pneumonia:}

Seven $(14 \%)$ cases of nonspecific interstitial pneumonia were reported in present study. Out of them, one (14\%) was male and six (86\%) were females. Four patients are serologically positive for connective tissue disorders which included one patient with rheumatoid arthritis and three scleroderma patients.

Chest radiographs studied in all seven cases showed reticular opacities in four cases and the rest demonstrated no significant abnormality. Majority of these cases presented with septal thickening $(n=7)$ with patchy areas of ground glass opacities $(n=5)$ on HRCT followed by bronchial dilatation $(n=3)$ and patchy honeycombing $(n=2)$. HRCT findings predominantly involved the lower lobes and subpleural regions like IPF but the distribution was patchy in contradictory to IPF which showed diffuse distribution of all findings. Honeycombing was also less common than IPF/UIP. These findings are in accordance with those reported by TS Kim et al. ${ }^{[24]}$ and Elliot TL et al. ${ }^{[25]}$

Scleroderma patients showed significant association with nonspecific interstitial pneumonia (43\%) and the commonly found associated findings observed on HRCT were dilated oesophagus and subpleural lines in our study. In most of the cases the lung volumes were preserved. 
with associated rheumatoid arthritis was reported in a study.

\section{Acute interstitial pneumonia:}

Seven (14\%) cases of acute interstitial pneumonia were identified. Out of seven, four $(58 \%)$ were males and three (42\%) were females. HRCT showed patchy areas of ground glass opacity with discrete areas of alveolar consolidation involving both lungs with predominant involvement of upper lobes (4 cases) and subpleural regions; which were consistent with the findings of Primack SL et al. ${ }^{[26]}$ and Bonaccorsi A et al. ${ }^{[27]}$

Three of the cases $(42 \%)$ died within seven days of the onset of acute symptoms. Out of these three cases one was serologically positive for SLE with traction bronchiectasis. Second case is associated with chemotherapy (ABVD regime: Adriamycin, Bleomycin, vincristine and Doxorubicin)for Hodgkin's lymphoma. Third case showed superimposition of bacterial infection in addition to viral etiology and associated with diabetes mellitus and acute renal failure. The findings nonsurvival of patients correlated with observations made by Kazuya Ichikado et al. ${ }^{[28]}$ where in nonsurvival was noted in 10 cases $(32.5 \%)$ out of 31 cases of AIP.

Additional findings such as bilateral pleural effusion (4 cases), cardiomegaly and paratracheal nodes were observed. Most common pattern observed on HRCT and chest radiograph is increased lung opacity due to consolidation and ground glass haziness.

Cryptogenic organising pneumonia/ bronchiolitis obliterans organising pneumonia:

Five (10\%)cases of cryptogenic organizing pneumonia were observed out of which one $(20 \%)$ was male and $4(80 \%)$ were females. Common chest radiographic findings included bilateral patchy areas of consolidation showing subpleural and lower lung zone predominance in three cases. High-resolution CT (HRCT) findings consist of ground glass opacities $(80 \%)$ and/or consolidative areas $(80 \%)$ distributed along the bronchovascular bundles and along the subpleural lungs. These findings correlated with study done by Ju Won Lee et al. ${ }^{[29]}$

Additional findings noted were pleural thickening and bronchiectasis seen in two cases $(40 \%)$. One patient with past history of allergic pneumonitis reveled additional findings such as mosaic perfusion and air trapping. Centrilobular emphysema was seen in a nonsmoker patient of BOOP/COP in our study.

\section{Hypersensitivity pneumonitis:}

One $(2 \%)$ case of subacute hypersensitivity pneumonitis was observed in a young boy having allergy to dust and presenting with chronic history of dry cough, dyspnea and fever. On chest radiograph reticulonodular opacities were seen. Diffuse involvement was noted on HRCT which included tiny centrilobular nodules with groundglass haziness and predominance in upper lobes. These findings were correlated with study done by DA lynch et al. ${ }^{[30]}$ and Zampatori $\mathrm{M}$ et al. ${ }^{[31]}$

\section{Sarcoidosis}

One (2\%) case of biopsy proven pulmonary sarcoidosis
Chest radiograph showed reticular pattern and HRCT revealed patchy distribution of septal thickening, peripheral and random nodules. These findings correlated with study done by Nishimura K et al. ${ }^{[32]}$ and Mimori Y et al. ${ }^{[33]}$

\section{Plexogenic arteriopathy:}

Two (4\%) cases of plexogenic arteriopathy associated with mixed connective disorder and congenital heart disease with pulmonary arterial hypertension were reported in the present study. HRCT findings observed were mosaic perfusion without air trapping in 2 cases, suggestive of basic pathology in vessels rather than bronchial pathology. Additional findings were dilated main pulmonary artery, centrilobular nodules and consolidation.

\section{Pulmonary Vasculitis:}

One (2\%) case of pulmonary vasculitis which was serologically positive for C-ANCA, P-ANCA, and ANA; suggestive of Wegener's Granulomatosis was reported in present study. BAL study showed active pulmonary hemorrhage and biopsy of skin lesions was suggestive of leucoclastic vasculitis. Chest radiograph revealed reticulonodular opacities. Patient also had history of smoking. HRCT showed patchy areas of ground glass opacity, consolidation, centrilobular nodule, septal thickening and traction bronchiectasis with collapse of apical segment of left lower lobe.

\section{Coal worker's pneumoconiosis:}

One (2\%) case of coal worker pneumoconiosis was reported in the present study in a patient who had history of more than 25 year exposure to coal particles in coal mine as a coal mine worker. Chest radiograph showed ill-defined reticulonodular opacities in bilateral lung fields with right sided pleural effusion. HRCT revealed mild smooth interstitial thickening in subpleural location predominantly in both lower lobes with multiple enlarged discrete mediastinal nodes measuring $8-15 \mathrm{~mm}$ in short axis and minimal bilateral pleural effusions. In a study done by Marchiori E et al, ${ }^{[34]}$ in silicosis, nodular masses and calcification of mediastinal lymph nodes were more common and in our study we found that septal thickening and few enlarged mediastinal lymph nodes without calcification in coal worker pneumoconiosis. These two conditions were difficult to differentiate on HRCT without clinical data and histopathology.

\section{Rheumatoid Arthritis:}

Eleven $(22 \%)$ cases which were serologically positive for rheumatoid arthritis were reported in our study. Out of eleven, one was $(9 \%)$ male and ten $(91 \%)$ were females showing a clear female preponderance. Most common pattern found with rheumatoid arthritis was reticular opacity associated with UIP /fibrosing alveolitis in our study. These findings correlated with J K Dawson et al. ${ }^{[35]}$ and Kinoshita Fet al. ${ }^{[36]}$

\section{Systemic Lupus Erythematosus:}

Two (4\%) cases which were serologically positive for systemic lupus erythematosus were reported in our study. Out of two, one case showed features of acute interstitial 
pneumonia and another case showed focal involvement of ground glass opacity in left lower lobe which may represent early changes of inflammation associated with SLE. The findings in the first patient correlate with lung involvement in SLE (Fenlon HM et al. ${ }^{[37]}$ and Ooi GC et al). ${ }^{[38]}$ The findings in the second patient are nonspecific in nature.

\section{Progresive systemic sclerosis (scleroderma):}

Four (8\%) cases which were serologically positive for scleroderma were reported in our study. Out of four, three $(75 \%)$ cases showed NSIP pattern and remaining one case showed UIP pattern with preserved lung volume. Few of these findings and association with interstitial lung disease correlated with studies done by Chan TY et al. ${ }^{[39]}$ and JmSeelyet al. ${ }^{[40]}$ In our study we found a strong correlation between scleroderma and NSIP pattern.

\section{Conclusion}

The present study included 50 patients with suspected interstitial lung disease of differing age groups. Out of these 44 patients showed specific pattern on HRCT. Most of the patients presented with complaints of breathlessness, dry cough, and joint pain.

HRCT was superior to chest radiograph in detection of all basic patterns and their distribution associated with ILD. Specific patterns related to ILD were observed in fourty four patients on HRCT and thirty three patients on chest radiograph. Chest radiograph is a nonspecific investigation and can be utilized as initial investigation in work up of ILD.As compared to chest radiographs; HRCT is capable of detecting disease processes much earlier in their evolution. UIP/IPF is the most common ILD and affects the basal and peripheral areas of the lung. They are characterized on HRCT images by the presence of reticular opacities, often associated with their typical presentation as traction bronchiectasis and honeycombing. Ground-glass opacity is also seen but is usually less extensive than the reticular pattern. Architectural distortion, which reflects lung fibrosis, is often prominent. Most cases of UIP/IPF showed decreased lung volume. Predominant pattern found in UIP/IPF was reticular opacity followed by decreased opacity.

NSIP is characterized by ground glass opacities which is its salient feature and is associated with reticulation, bronchiectasis and microcystic honeycombing. Predominant pattern found in NSIP was reticular opacity followed by increased opacity and decreased opacity.

AIP usually presents with acute onset of symptoms with severe breathlessness. It is characterized by patchy areas of ground glass opacities and consolidation predominantly in upper lobes associated with septal thickening and pleural effusion. Crazy paving pattern, which is combination of ground glass opacities and septal thickening, was noted. Predominant pattern found in AIP was increased opacity followed by reticular opacity.

COP/BOOP was seen as patchy areas of consolidation (subpleural or peribronchial distribution) with ground glass opacities. Predominant pattern found in COP/BOOP was increased opacity followed by decreased opacity.

Hypersensitive pneumonitis, plexogenic arteriopathy, sarcoidosis, pulmonary vasculitis and coal worker pneumoconiosis showed typical features on HRCT.

Collagen vascular disease was the most common associated factor with interstitial lung disease. Although HRCT findings of IPF and pulmonary involvement of CVD were seen to overlap considerably, patients with IPF showed a tendency to more fibrosis than with patients of CVD. Rheumatoid arthritis and scleroderma showed significant association with UIP and NSIP pattern respectively. Pulmonary vasculitis was seen in a patient with wegener's granulomatosis and sarcoidosis was seen in a patient with rheumatoid arthritis in the present study.

High resolution computed tomography is very effective in visualizing the distorted architecture of lung parenchyma in interstitial lung disease. Clinical evaluation, chest radiography and HRCT examination should be regarded as integral components of the investigation protocol in patients with various interstitial lung diseases. Based on the HRCT features a specific diagnosis can be reached in most cases of interstitial lung disease obviating the need for biopsy.

The findings of this study correlate well with many other studies reported in literature that emphasized the role of High Resolution Computed Tomography as a standard investigation to identify and quantify anatomic pattern and distribution of various interstitial lung diseases.

\section{References}

1. Behr J, Ryu JH. Pulmonary hypertension in interstitial lung disease. Eur Respir J 2008; 31:1357-67

2. American Thoracic Society. Idiopathic pulmonary fibrosis: diagnosis and treatment. International consensus statement. American Thoracic Society (ATS),and the European Respiratory Society (ERS). Am J Respir Crit Care Med 2000;161:646-64.

3. Ryu J, Daniels C, Hartman T, ES Yi. Diagnosis of interstitial lung diseases. Mayo Clin Proc 2007:82:976-86.

4. Raghu G, Nyberg F, Morgan G.The epidemiology of interstitial lung disease and its association with lung cancer. Br J Cancer 2004;91:3-10.

5. British Thoracic Society and Standards of Care Committee. The diagnosis, assessment and treatment of diffuse parenchymal lung disease in adults. Introduction. Thorax 1999;54 (1):1-14.

6. Selman M, Chapela R, Raghu G. Hypersensitivity pneumonitis: clinical manifestations, diagnostic and therapeutic strategies. Semin Respir Med 1993;14:353-64.

7. Sharma RP, Kaur G, Arora A, Khalasi Y, Vohra PV. Interstitial lung disease in rheumatoid arthritis: a study of thirty cases. Chest 2006;16:8359.

8. Raghu G, Brown KK. Interstitial lung disease: clinical evaluation and keys to an accurate diagnosis. Clin Chest Med 2004;25:409-19.

9. Muhammed SK, Anithkumari K, Fathahudeen A, Jayprakash B, et al. Aetiology And Clinic-Radiological Profile Of Interstitial Lung Disease In A Tertiary Care Centre. J Pulmon 2011; 13(1):12-15.

10. Sen T, Udwadia ZF. Retrospective Study of Interstitial Lung Disease in a Tertiary Care Centre in India.Indian J Chest Dis Allied Sci 2010; 52: 207211.

11. Maheshwari U, Gupta D, Aggarwal AN, Jindal SK. Spectrum and Diagnosis of Idiopathic Pulmonary Fibrosis. Indian J Chest Dis Allied Sci 2004:46:23-26

12. AzizZA, Wells AU, Hansell DM, Bain GA, et al. HRCT Diagnosis Of Diffuse Parenchymal Lung Disease: Interobserver Variation, Thorax 2004:59:506-511

13. Paslawski M, Kurys E, Zlomaniac J et al. Differentiation of linear and reticular opacities in high resolution computed tomography (HRCT) in interstitial lung disease. Ann UnivMariacMariaeSklodowska (Med) 2003; 58(2):378-385. 
14. Potente G, Bellelli A, Nardis P. Specific diagnosis by CT and HRCT in six chronic lung diseases. Comput Med Imaging Graph. 1992; 16(4):277-282

15. Grenier P, Chevret S, Beijelman $\mathrm{C}$ et al. Chronic diffuse infiltrative lung disease: Determination of the diagnostic value of clinical data. Chest radiography and CT with Bayesian Analysis. Radiology 1994; 191:383390

16. Aziz ZA, Wells AU, BatemanED, CopleySJ,et al. Interstitial Lung Disease: Effects of Thin-Section CT on Clinical Decision Making Radiology 2006: 238 (2)

17. Raniga S, Sharma P, Kaur G, Arora A, et al. Interstitial Lung Disease (IId) in Rheumatoid Arthritis (RA). IJRI 16 (4):835-839

18. Shabbier G, Amin S, Ullah F, Rehman S, Khan S. Role of high resolution Computed Tomographic Scan in diagnosis of Interstitial Lung Diseases in local population. J Postgrad Med Inst 2012; 26(2): 149-52

19. Lim MK, Im JG, Ahn JM, Kim JH, Lee SK, Yeon KM. Idiopathic pulmonary fibrosis versus pulmonary involvement of collagen vascular disease: HRCT findings. J Korean Med Sci. 1997; 12(6):492-498

20. Battista G, Zompatori $M$ et al. Progressive worsening of idiopathic pulmonary fibrosis. High resolution computed tomography (HRCT) study with functional correlation: Radiol Med.2003; 105(1-2):2-1 1.

21. Akira M, Sakatani M et al. Idiopathic pulmonary fibrosis: Progression of honeycombing at thin section CT: Radiology. 1993; 189(3):687-691.

22. Nishiyama O, Taniguchi H, Kondoh Y, Kimura T, Katoh T, Oishi T, Matsumoto S, Yokoi T, Takagi K et al. Familial idiopathic pulmonary fibrosis: Serial high resolution computed tomographic findings in 9 patients: J Comput Assist Tomogr. 2004; 28(4):443-448

23. Misumi S, Lynch DA. Idiopathic pulmonary fibrosis/Usual interstitial pneumonia: Imaging diagnosis, spectrum of abnormalities and temporal progression: Proc Am Thorac Soc. 2006; 3(4):307-314

24. TS Kim, Lee KS et al. Nonspecific interstitial pneumonia with fibrosis: high resolution CT and pathologic findings. AJR Am J Roentgenol 1998; 171:1645-1650

25. Elliot TL, Lynch DA et al. High-resolution computed tomography features of nonspecific interstitial pneumonia and usual interstitial pneumonia. J Comput Assist Tomogr.2005; 29(3):339-345

26. Primack SL, Hartman TE et al.Acute interstitial pneumonia: radiographic and CT findings in nine patients.Radiology 1992; 188:817-820.

27. Bonaccorsi A, CancellieriA et al. Acute interstitial pneumonia: Report of series. Eur Respir J 2003; 21(1): 187-191.

28. KIchikodo, MoritakaSuga et al. Acute interstitial pneumonia: Comparison of high resolution CT findings between Survivors and Nonsurvivors. AJR and Crit Care Med. 2002; 165:1551-1556.

29. Ju Won Lee, Kyung Soo Lee, Ho Yun Lee, Man Pyo Chung et.al.Cryptogenic Organizing Pneumonia:Serial High-Resolution CT Findingsin 22 Patients. AJR:195, October 2010;916-922.

30. DA Lynch, CS Rose, D Way, TE King Jr et al. Hypersensitivity pneumonitis: Sensitivity of high resolution CT in a population based study: American Journal of Roentgenology. 1992; 159:469-472

31. Zampatori M, Calabro E, Chetta A, Chiari G, Marangio E, Olivieri D. Chronic hypersensitivity pneumonitis or idiopathic pulmonary fibrosis? Diagnostic role of high resolution computed tomography (HRCT). Radiol Med (Torino) 2003; 106(3): 135-146.

32. Nishimura $\mathrm{K}$, Itoh $\mathrm{H}$, Kitaichi $\mathrm{M}$ et al. pulmonary sarcoidosis: Correlation of CT and histopathologic findings. Radiology 1993; 189:105-109

33. Mimori Y et al. Sarcoidosis correlation of HRCT findings with results of pulmonary function tests and serum angiotensin - converting enzyme assay. Kurume med J. 1998; 45(3):247-256.

34. Marchiori E, Ferreira A, Saez F, Gabetto JM, Souza AS Jr, Escuissato DL, Gasparetto EL et al. Conglomerated masses of silicosis in sand blasters: high - resolution CT findings. Eur J Radiol. 206; 59(1):56-59.

35. JK Dawson, HE Feuins, J Desmond, MP Lynch, DR Graham. Fibrosing alveolitis in patients with rheumatoid arthritis as assessed by high resolution computed tomography, chest radiography and pulmonary function tests. Thorax 2001; 56:622-627

36. Kinoshita F, Hamano H, Haroda H, Kinoshita T, Igishi T, Hagino H et al Role of KL - 6 in evaluating the disease severity of rheumatoid lung disease: comparison with HRCT. Respir Med. 2004; 98(11):1131-1137

37. Fenlon HM, Dran M et al. High resolution chest CT in systemic lupus erythematosus. AJR Am J Roentgenol. 1996; 166:301-307

38. Ooi GC, Ngan H, Peh WC, Mok MY, Ipm et al. Systemic lupus erythematosus patients with respiratory symptoms: the value of HRCT. Clin Radiol. 1997; 52(10):775-781.

39. Chan TY, Hansell DM et al. Cryptogenic fibrosing alveolitis and the fibrosing alveolitis of systemic sclerosis: Morphologic differences on computed tomographic scan. Thorax 1997; 52:265-270-

40. JM Seely, Jones LT, Wallace et al. Systemic sclerosis: using high resolution CT to detect lung disease in children. AJR Am J Roentgenol. 1998; 170:691-697

Copyright: (c) the author(s), publisher. Asian Journal of Medical Radiological Research is an Official Publication of "Society for Health Care \& Research Development". It is an open-access article distributed under the terms of the Creative Commons Attribution Non-Commercial License, which permits unrestricted non-commercial use, distribution, and reproduction in any medium, provided the original work is properly cited.

How to cite this article: Annapurna S, Badarke P, Chandra E. Study of Interstitial Lung Disease with Reference to Radiological Profile. Asian J. Med. Radiol. Res. 2018;6(1):15-21.

DOI: dx.doi.org/10.21276/ajmrr.2018.6.1.5

Source of Support: Nil, Conflict of Interest: None declared. 